\title{
PENGARUH KOMPENSASI TERHADAP FRAUD DENGAN KEPUASAN KERJA EBAGAI VARIABEL INTERVENING
}

\author{
Eka Prasetya Argarini \\ Prodi Akuntansi Universitas negeri Yogyakarta \\ Ekaprasetya210592@gmail.com
}

\begin{abstract}
Abstrak: Pengaruh Kompensassi Terhadap Fraud dengan Kepuasan Kerja sebagai Variabel Intervening. Penelitian ini termasuk penelitian kausal komparatif bertujuan untuk mengetahui pengaruh: (1) Kompensasi terhadap Fraud pada BMT di Wonosari, (2) Kepuasan Kerja terhadap Fraud pada BMT di Wonosari, (3) Kompensasi terhadap Fraud melalui Kepuasan Kerja sebagai variabel intervening pada BMT di Wonosari. Penelitian ini adalah penelitian populasi dengan subjek penelitian yaitu 66 karyawan yang bekerja pada 5 BMT di Wonosari. Data penelitian diperoleh melalui distribusi kuesioner. Uji keandalan instrumen meliputi uji validitas dan uji reabilitas. Uji asumsi klasik meliputi uji linearitas, uji multikolinearitas, dan uji heteroskedastisitas. Regresi linier sederhana dan Bootstrapping digunakan untuk menguji hipotesis.Hasil penelitian ini menunjukkan bahwa (1) Kompensasi berpengaruh negatif terhadap Fraud, dibuktikan nilai koefisien regresiX sebesar $-0,593$ dan nilai t hitung lebih besar dari t tabel yaitu 3,155>1,998, persamaan regresi $\mathrm{Y}=$ 35.174-0,593X1; (2) Kepuasan Kerja berpengaruh negatif terhadap Fraud, dibuktikan dengan nilai koefisien regresi $\mathrm{X}_{2}-0,342$ dan nilai $\mathrm{t}$ hitung lebih besar daripada $t$ tabel 5,748>1,998, persamaan regresi 37.076-0,342X2; (3) Kepuasan Kerja memediasi hubungan Kompensasi terhadap Fraud, dibuktikan dengan nilai t hitung lebih besar dari t tabel yaitu 3,637>1,998 dengan signifikansi $0,004<0,05$.
\end{abstract}

Kata Kunci: Fraud, Kompensasi, Kepuasan Kerja.

Abstract: The Effect Of Cpmpensation on Fraud With Job Satisfaction as Intervening Variable. This research was aimed to determine the effect of : (1.) Compensation on Fraud at BMT in Wonosari, (2.) Job satisfaction on Fraud at BMT in Wonosari, (3.) Compensation on Fraud with Job satisfaction as intervening variable at BMT in Wonosari. It is a research that involves the whole population consist of 66 employees working in five BMT in Wonosari. The study categorized as research study using data collection from questionnaires distribution. Instrument reliability test include validity and reliability test. Classical assumption tests include: multicolinierity, linierity, and heteroskedacity. Hyphoteses were examined using simple regression analysis and bootstrapping. The results show that: (1.) Compensation negatively influences Fraud, the coefficient of regression is 0,593 and value of $t$ count 3,155> $t_{\text {table }} 1,998$, (2.) Job satisfaction is negatively influences Fraud, the coefficient of regression is $-0,342$ and value of $t_{\text {count }} 5,748>t$ table 1,998 , (3.) Compensation negatively influences Fraud through Job satisfaction, $t_{\text {count }} 3,637>t_{\text {table }} 1,998$ with significance 0,004<0,005.

Keyword: Fraud, Compensation, and Job Satisfaction

\section{PENDAHULUAN}

Fraud telah berkembang di berbagai negara termasuk di Indonesia. Secara harafiah Fraud didefinisikan sebagai kecurangan, namun pengertian ini telah dikembangkan lebih lanjut sehingga mempunyai cakupan yang luas. Fraud disini antara lain adalah manipulasi, penggelapan, pencurian, dan tindakan buruk lainnya yang dilakukan oleh suatu 


\section{JURNAL NOMINAL / VOLUME IV NOMOR 2 / TAHUN 2015}

pihak yang dapat mengakibatkan kerugian bagi pihak lain atau perusahaan/organisasi. Sedangkan menurut Cressey dalam Tuanakotta (2007:105) Fraud disebabkan oleh tekanan, persepsi akan adanya peluang, dan rasionalisasi. Fraud dapat dilakukan oleh siapa saja termasuk pihak yang tidak memiliki jabatan tertentu sekalipun.

Menurut Sie Infokum dalam Andrian Budi Prasetyo (2011) bahwa pelaku Fraud dapat diklasifikasikan ke dalam dua kelompok, yaitu manajemen dan karyawan/pegawai. Pihak manajemen melakukan Fraud biasanya untuk kepentingan perusahaan. Pihak karyawan/pegawai melakukan Fraud bertujuan untuk keuntungan individu. Apabila dikaitkan dengan model segitiga kecurangan, fakta ini relevan dengan teori terjadinya Fraud antara lain harus ada kesempatan dan kesempatan umumnya lebih dipahami oleh orang dalam termasuk manajer, karyawan, dan pihak-pihak lainnya.

Karyawan memegang peranan penting dalam menentukan keberhasilan perusahaan. Selain sebagai sumber daya manusia yang sangat penting dalam menentukan keberhasilan suatu perusahaan, disisi lain karyawan juga merupakan makhluk yang mempunyai pikiran, perasaan kebutuhan dan harapanharapan tertentu. Karyawan tentu saja mengharapkan adanya timbal balik yang berupa Kompensasi atas kontribusi yang sesuai dengan apa yang dilakukan karyawan terhadap perusahaan. Kompensasi yang sesuai diyakini dapat mendorong karyawan untuk meningkatkan kinerjanya sedangkan Kompensasi yang tidak sesuai diyakini mampu mendorong karyawan untuk melakukan tindakan Fraud.

Hal lain yang membuat karyawan melakukan Fraud adalah tekanan yang disebabkan rendahnya tingkat kepuasan dalam pekerjaan (work related pressure). Kepuasan Kerja dibentuk oleh imbal jasa yang diberikan pada anggota organisasi atau karyawan yang telah memberikan kontribusi pada organisasi (Budi Haryanto, 2008). Sementara itu menurut M. As'ad (2003:102), faktor-faktor yang mempengaruhi Kepuasan Kerja adalah faktor utama dalam pekerjaan yang meliputi upah/gaji, pengawasan, ketentraman kerja, kondisi kerja dan kesempatan untuk maju; faktor individual; dan faktor sosial.

BMT yang terlibat kasus Fraud misalnya BMT Bumi Sejahtera Amanah yang berlokasi di Wonosari. Berdasarkan wawancara dengan sumber yang merupakan karyawan BMT terkait, BMT ini memiliki 30 orang karyawan yang terbagi atas $20 \%$ (6 orang) merupakan karyawan senior dan sisanya 24 orang 


\section{JURNAL NOMINAL / VOLUME IV NOMOR 2 / TAHUN 2015}

merupakan karyawan baru yang masingmasing memiliki tanggungjawab yang berbeda untuk melayani nasabah (disebut juga anggota). Karyawan diberikan tanggungjawab untuk mencari nasabah (anggota) baru dan membantu di bidang pembiayaan, dalam jumlah sesuai dengan target yang ditentukan BMT Bumi Sejahtera Amanah pada setiap bulannya. Dari tanggungjawab yang dibebankan kepada karyawan, BMT Bumi Sejahtera Amanah memberikan gaji kepada karyawan sesuai UMR Kab.Gunungkidul. Kebijakan yang diberlakukan di BMT Bumi Sejahtera Amanah adalah setiap karyawan diberikan bonus sebesar $0,7 \%$ dari pembiayaan yang berhasil dicapai. Karyawan juga diberi hak untuk menerima/menolak hadiah atau sejenisnya dari nasabah (anggota) baru sebagai bentuk "tanda terimakasih". Selain itu, biaya transportasi karyawan dalam menjalankan tanggungjawabnya menjadi beban BMT, karyawan hanya diharuskan menyetorkan bukti transaksi berupa nota bensin kepada BMT untuk kemudian diganti dengan uang tunai.

Pada 2012 terungkap kejadian Fraud yang dilakukan oleh karyawan BMT Bumi Sejahtera Amanah dan terpaksa harus berurusan dengan pihak berwajib karena terbukti telah melakukan tindak kecurangan berupa penggelapan/korupsi dana nasabah sejumlah ratusan juta rupiah.
Kasus tersebut terungkap setelah adanya beberapa nasabah yang melapor. Menanggapi laporan dari nasabah, pihak BMT pun melakukan penelusuran lebih lanjut. Dari penyelidikan ditemukan bahwa ternyata dana yang nasabah setorkan ke bank tidak tercatat ke dalam sistem pembukuan BMT. Hal ini terjadi bukan karena faktor kesalahan entri data atau sebagainya melainkan merupakan faktor kesengajaan yang dilakukan oleh pihak yang tidak bertanggungjawab untuk kepentingan keuntungan pribadi.

Dari contoh kasus diatas, Kompensasi dan Kepuasan Kerja diduga memiliki kaitan yang erat dengan Fraud. Kompensasi merupakan salah satu indikator dalam menentukan tingkat kepuasan yang dirasakan oleh karyawan yang pada akhirnya turut berperan pada niatan melakukan tindakan Fraud. Karel A. Leklikwati (2005) dalam penelitiannya mengemukakan bahwa kompensasi finansial dan kompensasi non finansial teruji berpengaruh positif dan signifikan terhadap Kepuasan Kerja, dimana artinya bahwa semakin baik persepsi responden terhadap kompensasi finansial dan kompensasi non finansial akan menyebabkan tingginya Kepuasan Kerja. Pada BMT Bumi Sejahtera Amanah, jumlah Kompensasi yang diterima karyawan tidak cukup besar jika dibandingkan dengan tanggungjawab yang 
dibebankan. Karyawan yang keluar-masuk cukup banyak, hanya $20 \%$ dari total karyawan yang masih bekerja pada BMT Bumi Sejahtera Amanah merupakan karyawan senior.

Berdasarkan uraian kasus tersebut, maka peneliti tertarik untuk melakukan penelitian yang berjudul "Pengaruh Kompensasi terhadap Fraud dengan Kepuasan Kerja sebagai Variabel Intervening" untuk mengetahui apakah Kompensasi dan Kepuasan Kerja merupakan faktor yang mendorong karyawan dalam melakukan tindakan Fraud, dengan subjek penelitian meliputi karyawan BMT Bumi Sejahtera Amanah, BMT Mitra Utama, BMT Pertiwi Jaya, BMT Berkah, dan BMT Pelita Insan di Wonosari.

\section{METODE PENELITIAN}

\section{Jenis Penelitian}

Jenis penelitian ini adalah penelitian kausal komparatif. Penelitian kausal komparatif merupakan tipe penelitian dengan karakteristik masalah berupa hubungan sebab akibat antara dua variabel atau lebih (Nur Indriantoro dan Bambang Supomo, 2002:27). Penelitian ini berbentuk penelitian survey karena mengumpulkan informasi dari responden menggunakan kuesioner/angket. Penelitian survey adalah penelitian yang secara langsung dilakukan kepada suatu populasi yang dipilih sebagai objek penelitian dan menggunakan kuesioner sebagai alat pengumpulan data yang pokok.

\section{Waktu dan Tempat Penelitian}

Penelitian ini dilaksanakan pada 5 BMT di wilayah Wonosari yaitu BMT Bumi Sejahtera Amanah, BMT Mitra Utama, BMT Pertiwi Jaya, BMT Berkah, dan BMT Pelita Insan. Penelitian ini dilaksanakan pada bulan Februari sampai dengan Oktober 2015.

\section{Subjek Penelitian}

Subjek dalam penelitian ini adalah seluruh karyawan dari BMT Bumi Sejahtera Amanah, BMT Mitra Utama, BMT Pertiwi Jaya, BMT Berkah, dan BMT Pelita Insan yang berjumlah 98 orang. Dari 5 BMT tersebut BMT Bumi Sejahtera Amanah digunakan sebagai uji coba instrumen dan keempat BMT lainnya digunakan sebagai subjek penelitian. Untuk mencegah bocornya pertanyaan dalam kuesioner maka yang digunakan sebagai uji coba instrumen hanya karyawan BMT Bumi Sejahtera Amanah.

Data, Instrumen, dan Teknik, Pengumpulan.

Sumber data yang digunakan oleh peneliti adalah data primer. Data primer merupakan data yang didapat dari sumber pertama seperti hasil dari wawancara atau 


\section{JURNAL NOMINAL / VOLUME IV NOMOR 2 / TAHUN 2015}

hasil pengisian kuesioner yang biasa dilakukan oleh peneliti.

Penelitian ini menggunakan instrumen berupa kuisioner/daftar pertanyaan yang berisi tentang variabel terikat (Fraud), variabel intervening (Kepuasan Kerja) dan variabel bebas (Kompensasi) yang menggunakan skala sikap model likert yang dimodifikasi dengan 4 jawaban. Skala likert digunakan untuk mengukur sikap, pendapat, dan persepsi orang mengenai suatu permasalahan yang terjadi.

\section{Teknik Analisis Data}

1. Statistik Deskriptif

Statistik deskriptif memberikan gambaran atau deskripsi suatu data yang dilihat dari nilai minimum, nilai maksimum, rata-rata hitung(mean), dan standar deviasi (standard deviation). Menurut Uma Sekaran (2006:176), statistik deskriptif dimaksudkan untuk memberikan gambaran yang baik tentang bagaimana responden bereaksi terhadap item dalam kuesioner.

\section{Uji Keandalan Instrumen}

Uji keandalan instrumen dilakukan untuk mengukur validitas dan reliabilitas instrumen penelitian yang akan digunakan dalam pengambilan data. Dalam penelitian ini, Uji Validitas dan Uji Reliabilitas dilakukan pada 30 karyawan dari BMT Bumi Sejahtera Amanah. Karyawan yang digunakan dalam uji coba instrumen tidak digunakan sebagai subjek penelitian.

Dalam penelitian ini uji validitas dilakukan dengan menggunakan korelasi dengan format Pearson Correlation, korelasi antar skor item kemudian dibandingkan dengan nilai kritis. Dimana apabila nilai $r_{\text {hitung }}$ di atas nilai $r_{\text {tabel }}(0,361)$ maka dapat dikatakan valid, sedangkan bila nilai $r_{\text {hitung }}$ di bawah nilai $r_{\text {tabel }}(0,361)$ maka dikatakan tidak valid.

Tabel 1. Hasil Uji Validitas Instrumen Penelitian.

\begin{tabular}{ccccc}
\hline No & Var & $\begin{array}{c}\text { Jumlah } \\
\text { Butir }\end{array}$ & Valid & $\begin{array}{c}\text { Tidak } \\
\text { Valid }\end{array}$ \\
\hline $\mathbf{1}$ & $\mathrm{Y}$ & 10 & 10 & - \\
$\mathbf{2}$ & $\mathrm{X}_{1}$ & 10 & 8 & 2 \\
$\mathbf{3}$ & $\mathrm{X}_{2}$ & 12 & 11 & \\
\hline \multicolumn{5}{l}{ Sumber: Data primer } \\
yang diolah 2015
\end{tabular}

Pengukuran reliabilitas dilakukan dengan uji statistik Cronbach Alpha. Menurut Sekaran, (2005: 132) dalam Norayu (2010) suatu variabel dikatakan memiliki korelasi kuat jika memberikan nilai Cronbach Alpha > 0,6.

Tabel 2. Uji Reabilitas Instrumen Penelitian

\begin{tabular}{cccc} 
No & Var & $\begin{array}{c}\text { Cronbach } \\
\text { Alpha }\end{array}$ & Keterangan \\
\hline $\mathbf{1}$ & $\mathrm{Y}$ & 0,912 & Reliabel \\
$\mathbf{2}$ & $\mathrm{X}_{1}$ & 0,883 & Reliabel \\
$\mathbf{3}$ & $\mathrm{X}_{2}$ & 0,945 & Reliabel \\
\hline \multicolumn{3}{l}{ Sumber: Data primer yang diolah 2015 }
\end{tabular}

Berdasarkan tabel di atas, instrumen dari masing-masing variabel dalam 
JURNAL NOMINAL / VOLUME IV NOMOR 2 / TAHUN 2015

penelitian ini reliabel dan dapat digunakan dalam penelitian.

\section{Uji Asumsi Klasik}

Uji asumsi klasik dalam penelitian ini meliputi uji multikolinearitas bertujuan untuk menguji apakah dalam persamaan regresi ditemukan adanya korelasi antar variabel bebas (independen), uji linearitas dilakukan untuk mengetahui apakah dua variabel mempunyai hubungan yang linear atau tidak secara signifikan, dan uji heteroskedasisitas digunakan untuk menguji apakah dalam sebuah model regresi terjadi ketidaksamaan varian dari residual suatu pengamatan ke pengamatan lain.

\section{Uji Hipotesis}

Uji hipotesis dalam penelitian ini menggunakan analisis regresi sederhana untuk hipotesis 1, dan 2,; dan Bootstrapping untuk hipotesis 3. Pada analisis regresi sederhana, hipotesis diterima apabila thitung lebih besar dari tabel pada taraf signifikansi 5\%, dan didukung pula apabila signifikansi lebih kecil daripada level of significant $(\operatorname{sig}<\alpha)$ yaitu sebesar 0,05 (Husein Umar, 2011). Pada Bootstrapping, nilai $\mathrm{t}$ hitung ini dibandingkan dengan nilai $\mathrm{t}$ tabel, jika nilai $\mathrm{t}$ hitung > nilai t tabel maka dapat disimpulkan terjadi pengaruh mediasi dari variabel intervening tersebut.
HASIL PENELITIAN DAN PEMBAHASAN

Penelitian ini dilaksanakan pada karyawan BMT Bumi Sejahtera Amanah, BMT Mitra Utama, BMT Pertiwi Jaya, BMT Berkah, dan BMT Pelita Insan di Wonosari.Penyebaran kuesioner dilakukan pada bulan Mei 2015.Kuesioner yang disebar sebanyak 68 kuesioner. Dari keseluruhan kuesioner yang disebar, sebanyak 2 kuesioner tidak diisi lengkap dan tidak dapat dianalisis lebih lanjut. Total kuesioner yang digunakan sebagai bahan analisis adalah sejumlah 66 buah. Karakteristik responden yang menjadi subjek dalam penelitian ini dikelompokkan berdasarkan usia, lamanya bekerja, dan jenjang pendidikan yang pernah ditempuh.

Perhitungan nilai deskripsi statistik dari masing-masing variabel tersebut menghasilkan output sebagai berikut.

Tabel 3. Statistik Deskriptif Variabel

\begin{tabular}{llll}
\hline Keterangan & $\mathbf{Y}$ & $\mathbf{X}_{\mathbf{1}}$ & $\mathbf{X}_{\mathbf{2}}$ \\
\hline $\mathbf{N}$ & 66 & 66 & 66 \\
Mean & 19,33 & 26,73 & 51,92 \\
Median & 20,00 & 27,00 & 51,00 \\
Modus & 20 & 27 & 51 \\
Std. & 3,19 & 1,97 & 5,44 \\
Deviasi & & & \\
Minimun & 11 & 22 & 44 \\
Maximum & 27 & 31 & 67 \\
\hline \multicolumn{4}{l}{ Sumber: Data primer yang diolah 2015 }
\end{tabular}

1. Hasil Uji Asumsi Klasik

a. Uji Multikolinearitas

Hasil uji multikolinearitas dapat dilihat pada tabel berikut. 
JURNAL NOMINAL / VOLUME IV NOMOR 2 / TAHUN 2015

Tabel 4. Hasil Uji Multikolinearitas

\begin{tabular}{llll}
\hline $\begin{array}{l}\text { Variabel } \\
\text { Tabel }\end{array}$ & Tolerance & VIF & Ket \\
\hline $\begin{array}{l}\text { Kompen- } \\
\text { sasi }\end{array}$ & 0,639 & 1,565 & $\begin{array}{l}\text { Tidak } \\
\text { terjadi } \\
\text { multiko- } \\
\text { linearitas }\end{array}$ \\
$\begin{array}{l}\text { Kepuas- } \\
\text { an Kerja }\end{array}$ & 0,639 & 1,565 & $\begin{array}{l}\text { Tidak } \\
\text { terjadi } \\
\text { multikolin } \\
\text { earitas }\end{array}$ \\
\hline
\end{tabular}

Sumber: Data Primer yang diolah, 2015

Hasil perhitungan analisis menunjukkan bahwa nilai VIF setiap variabel independen adalah lebih kecil dari 10,0. Nilai tolerance setiap variabel juga lebih besar dari 0,1. Hal ini dapat disimpulkan bahwa tidak terjadi multikolinearitas.

Tabel 5. Hasil Uji Linearitas

\begin{tabular}{llll}
\hline Variabel & F & $\begin{array}{l}\text { D.f } \\
\text { Hitung }\end{array}$ & Ket. \\
\hline $\begin{array}{l}\text { Kompensasi } \\
\text { dengan Fraud }\end{array}$ & 0,873 & 0,545 & Linear \\
$\begin{array}{l}\text { Kepuasan Kerja } \\
\text { dengan Fraud }\end{array}$ & 0,728 & 0,759 & Linear \\
\hline \multicolumn{3}{l}{ Sumber: Data primer yang diolah 2015 }
\end{tabular}

Tabel diatas menunjukkan masingmasing variabel memiliki signifikansi linearitas kurang dari 0,05 jadi dapat disimpulkan jika variabel tersebut memenuhi syarat linier.

Tabel 6. Hasil Uji Heteroskedastisitas

\begin{tabular}{lllr}
\hline Variabel & Sig t & \multicolumn{2}{l}{ Keterangan } \\
\hline Kompensasi & 0,276 & $\begin{array}{l}\text { Tidak terjadi } \\
\text { heterokedastisitas }\end{array}$ \\
Kepuasan & 0,167 & $\begin{array}{l}\text { Tidak terjadi } \\
\text { heterokedastisitas }\end{array}$ \\
Kerja & & rang diolah 2015
\end{tabular}

Berdasarkan output dalam tabel tersebut menunjukkan bahwa semua variabel independen memiliki nilai probabilitas signifikansi yang lebih besar dari 0,05. Dapat disimpulkan bahwa tidak terjadi heteroskedastisitas dalam model regresi tersebut.

2. Uji Hipotesis

a. Analisis Linier Sederhana

Hipotesis 1: Kompensasi berpengaruh negatif terhadap Fraud.

Tabel. 7. Hasil Uji Hipotesis 1

\begin{tabular}{lccc}
\hline Variabel & $\begin{array}{c}\text { Koefisien } \\
\text { Regresi }\end{array}$ & t hitung & Sig \\
\hline Konstanta & 35.174 & & \\
$\mathbf{X}_{\mathbf{1}}$ & $-0,593$ & $-3,155$ & 0,002 \\
$\mathbf{R}$ & $\mathbf{0} \mathbf{0 , 3 6 7}$ & & \\
$\boldsymbol{R}$ Square & $\mathbf{0 , 1 3 5}$ & & \\
\hline \multicolumn{4}{l}{ Sumber: Data primer yang diolah 2015 }
\end{tabular}

Berdasarkan tabel tersebut dapat diketahui persamaan regresinya adalah $\mathrm{Y}=35.174$ 0,593X1. Hasil tersebut menunjukkan arah model regresi ini adalah negatif, yang berarti semakin tinggi Kompensasi yang diterima maka semakin rendah tingkat Fraud yang akan dilakukan oleh karyawan. Besarnya pengaruh Kompensasi terhadap Fraud dapat dilihat dari nilai R yaitu sebesar 0,367 atau 36,7 \%. Variabel Fraud dapat dijelaskan oleh variabel Kompensasi sebesar 13,5\%, sedangkan sisanya $86,5 \%$ dijelaskan oleh variabel variabel lain diluar penelitian ini. Maka hipotesis 1 yang menyatakan Kompensasi berpengaruh terhadap Fraud diterima. 
Hipotesis 2: Kepuasan Kerja berpengaruh negatif terhadap Fraud

Tabel. 8. Hasil Uji Hipotesis 2

\begin{tabular}{llll}
\hline Variabel & $\begin{array}{c}\text { Koefisien } \\
\text { Regresi }\end{array}$ & t hitung & Sig \\
\hline Konstanta & 37,076 & & \\
$\mathbf{X}_{\mathbf{2}}$ & $-0,342$ & $-5,748$ & 0,000 \\
$\mathbf{R}$ & $\mathbf{0} \mathbf{0 , 5 8 4}$ & & \\
$\boldsymbol{R}$ Square & $\mathbf{: 0 , 3 4 0}$ & & \\
\hline \multicolumn{4}{l}{ Sumber: Data primer yang diolah 2015}
\end{tabular}

Berdasarkan tabel tersebut dapat diketahui persamaan regresinya adalah $\mathrm{Y}=$ $37.076-0,342 \times 2$. Hasil tersebut menunjukkan arah model regresi ini adalah negatif, yang berarti semakin tinggi Kepuasan Kerja yang diterima maka semakin rendah tingkat Fraud yang akan dilakukan oleh karyawan. Besarnya pengaruh Kepuasan Kerja terhadap Fraud dapat dilihat dari nilai $\mathrm{R}$ yaitu sebesar 0,584 atau 58,4\%. Variabel Fraud dapat dijelaskan oleh variabel Kepuasan Kerja sebesar $34,0 \%$, sedangkan sisanya $66,0 \%$ dijelaskan oleh variabel variabel lain diluar penelitian ini. Maka hipotesis 2 yang menyatakan Kepuasan Kerja berpengaruh negatif terhadap Fraud diterima.

\section{b. Bootstrapping}

Hipotesis 3: Kompensasi berpengaruh terhadap Fraud dengan Kepuasan Kerja sebagai variabel intervening.
Tabel. 9. Hasil Uji Hipotesis 3

\begin{tabular}{lllll}
\hline X1 & X2 & Y & Value & Sig \\
\hline Ko & Kepuas & Fraud & 0,5518 & 0,004 \\
mpe & an & & \\
n & Kerja & \\
Sasi & \\
Sumber: Data primer yang diolah 2015 \\
$\mathrm{t}=\frac{\text { koefisien } \text { indirecteffect }}{\text { s.e(standarerror })}$ \\
$\mathrm{t}=\frac{-0,5518}{0,1517}$ \\
$=-3,637$
\end{tabular}

Kriteria pengujian jika nilai t hitung > nilai $\mathrm{t}$ tabel maka disimpulkan terjadi pengaruh mediasi dari variabel intervening. Pada penelitian ini dibuktikan nilai t penelitian sebesar 3,637 lebih besar dari ttabel pada tingkat signifikasi 5\% yaitu $1,998 \quad(3,637>1.998) \quad$ serta nilai probabilitas signifikansi sebesar 0,004 atau lebih kecil dari $0,05 \quad(0,050>$ 0,004).Pengujian ini membuktikan bahwa terjadi mediasi antara variabel Kompensasiterhadap Fraud melalui Kepuasan Kerja, sehingga dapat disimpulkan bahwa hipotesis ketiga dapat diterima.

\section{SIMPULAN DAN SARAN}

\section{Kesimpulan}

1. Kompensasi berpengaruh negatif terhadap Fraud.

2. Kepuasan Kerja berpengaruh negatif terhadap Fraud. 
3. Kepuasan Kerja merupakan variabel intervening antara Kompensasi terhadap Fraud.

\section{Saran}

1. Bagi BMT, sebaiknya menjelaskan secara rinci dari awal kepada nasabah mengenai kebijakan BMT terkait prosedur administrasi. Hal ini untuk mengurangi Fraud ketika terjadi pencairan dana pembiayaan nasabah.

2. BMT sebaiknya meningkatkan Kompensasi yang diberikan kepada karyawan terkait dengan gaji dan tunjangan, karena pada penelitian ini terbukti tingkat Kepuasan Kerja yang dirasakan karyawan mengenai jumlah gaji masih rendah. Dikhawatirkan apabila ini terus berlanjut akan mempengaruhi kemungkinan Fraud pada organisasi.

3. Bagi penelitian selanjutnya, sebaiknya menggunakan sampel penelitian yang lebih luas, karena pada penelitian ini sampel masih sempit yaitu hanya 5 BMT terkait sementara terdapat banyak BMT yang beroperasi di wilayah Wonosari.

\section{DAFTAR PUSTAKA}

Andrian Budi Prasetyo. (2011). "Kualitas Prosedur Pengendalian Internal: Analisis dan Pengaruh Moderating pada Keadilan Organisasional dan
Kecurangan Pegawai”. Skripsi.

Universitas Diponegoro.

Budi Haryanto. (2008). Pengaruh Budaya Organisasi dan Kepuasan Kerja terhadap Komitmen Organisasi di Kalangan Dosen Universitas Muhammadiyah Sidoarjo. Jurnal Emisi Vol. 1 No. 1.

Karel A. Lekliwati. (2005). Analisis Pengaruh Kompensasi Finansial dan Nonfinansial Terhadap Kepuasan Kerja Karyawan Perusahaan Daerah Air Minum Kabupaten Yapen Waropen, Papua. Jurnal Aplikasi Manajemen, 3(2), h: 111-117.

M. As'ad. (2003). Psikologi Industri : Seri Sumber Daya Manusia. Yogyakarta : Liberty.

Nur Indriantoro \& Bambang Supomo. (2002). Metode Penelitian Bisnis. Yogyakarta: BPFE.

Tuanakotta. (2007). Audit Forensik dan Audit Investigatif. Jakarta: Fakultas Ekonomi Universitas Indonesia.

Uma Sekaran. (2006). Metode Penelitian untuk Bisnis. Jakarta: Salemba Empat. 